\title{
ATUAÇÃO DA ENFERMEIRA JUNTO AO PACIENTE CIRÚRGICO NA PREVENÇÃO DE COMPLICAÇÕES PULMONARES
}

\author{
Maria Apparecida Valente* \\ Cilene Aparecida Costardi Ide**
}

VALENTE, M. A. \& IDE, C. A. C. Atuação da enfermeira junto ao paciente cirúrgico na prevenção de complicações pulmonares. Rev. Esc. Enf. USP, São Paulo, $16(3): 265-274,1982$.

$O$ presente artigo aborda assistência de enfermagem ao paciente cirúrgico, na prevenção e terapêutica de complicações pulmonares. As autoras discorrem sobre os fatores predisponentes das complicaçōes pulmonares (idade avançada, desequilibrios nutricional e de hidratação, exacerbação de doenças pulmonares obstrutivas crônicas) assim como sobre os fatores agravantes das mesmas (anestesia, imobilização no leito, distensão abdominal $\boldsymbol{e}$ dor). Apresentam os objetivos da assistência de enfermagem, a conduta preventiva no pré e pós-operatórios, a identificaşão precoce dos sinais clínico de insuficiência respiratória e o tratamento.

\section{INTRODUÇÃO}

As complicações pulmonares constituem os problemas mais freqüentemente apresentados pelos pacientes hospitalizados, com incidência de 20 a $40 \%$ nos indivíduos submetidos a cirurgia tóraco-abdominal ${ }^{2}$. Apresentam-se como algumas das principais causas de morbidade e mortalidade nas eventualidades citadas, tendo como mecanismo de base o colapso gradual e progressivo dos alvéolos, caracterizado pela tríade: hipoventilação, atelectasia e colapso pulmonar.

Grande parte destas intercorrências pode ser atribuída a assistência de enfermagem inadequada para propor, executar e avaliar medidas preventivas de controle e tratamento dessas complicações. Somente através de assistência de enfermagem sistematizada, cientificamente fundamentada, é que conseguiremos diminuir a incidência dessas intercorrências, como também evitar as iatrogenias ainda presentes nessas práticas.

E, portanto, objetivo do presente trabalho a proposição dessa assistência de enfermagem.

* Professor Assistente do Departamento de Enfermagem Médico-Cirúrgica da Escola de Enfermagem da USP - disciplina Enfermagem Médico-Cirúrgica I. Mestre em Enfermagem. Enfermeira.

** Auxiliar de Ensino do Departamento de Enfermagem Médico-Cirúrgica da Escola de Enfermagem da USP - disciplina Enfermagem Médico-Cirúrgica I. Enfermeira. 


\section{COMPLICAÇס̃ES PULMONARES MAIS COMUNS}

Independentemente da patologia de base que determinou a internação do paciente, a prevenção, a deteç̧ão precoce de sinais e sintomas de complicações pulmonares e o tratamento adequado das mesmas muito dependerão do preparo da equipe de enfermagem.

Entre as complicações mais comuns destacam-se a atelectasia e as infecções. Entende-se por atelectasia o colapso de unidade pulmonar ocasionado por três mecanismos básicos: retenção de secreção brônquica, ausência ou diminuição do mecanismo de suspiro e a diminuição de reserva respiratória. Entre as infecções que afetam a unidade pulmonar consideram-se desde a exacerbação da bronquite crônica até a pneumonia.

Essas complicações constituem situações de extrema gravidade que, se não forem prevenidas e/ou precocemente identificadas, levarão invariavelmente à insuficiência respiratória aguda, ou seja a incapacidade do aparelho respiratório em arterializar o sangue venoso, isto é, em enriquecê-lo de oxigênio $\left(\mathrm{O}_{2}\right)$ e despojá-lo de gás carbônico $\left(\mathrm{CO}_{2}\right)$; tal incapacidade pode acontecer com ou sem retenção de $\mathrm{CO}_{2}$, em uma ou mais das fases do processo respiratório.

\section{FATORES PREDISPONENTES E AGRAVANTES DAS COMPLICAÇŐES PULMONARES}

\section{Fatores predisponentes}

Como fatores predisponentes às complicações pulmonares podemos considerar: idade avançada, desequilíbrios nutricionais (desnutrição e obesidade), desequilíbrios de hidratação (desidratação e hiperidratação), exacerbação de doenças pulmonares obstrutivas crônicas (DPOC) bronquite crônica, asma e enfisema - e tabagismo.

Idade Avançada. Sabe-se que a capacidade pulmonar diminui com a idade, especialmente depois dos 50 anos; as condições cardiacas, renais e endócrinas, com o correr dos anos, também se encontram muitas vezes alteradas ${ }^{1}$.

Desequilibrios Nutricionais. Desnutrição é a condição que aumenta a susceptibilidade a perturbações do equilíbrio ácido-básico, do aparelho cárdio-respiratório, além de levar com freqüência a fenômenos tromboembólicos e a infecções da ferida operatória, com dificuldade na cicatrização dos tecidos devido à deficiência protéica. Pacientes desnutridos apresentam geralmente debilidade muscular progressiva, inclusive da musculatura respiratória, o que facilita o estabelecimento de infecções pulmonares; o paciente torna-se apático, deixando de cooperar na sua própria recuperação ${ }^{1, ~ ? ~}$.

Obesidade é condição que dificulta o trabalho respiratório pois, aumenta o consumo de $\mathrm{O}_{2}$ e, como conseqüência, há maior produção de 
$\mathrm{CO}_{2}$; isto faz com que, mesmo em repouso, o organismo necessite de maior ventilação alveolar, resultando pressão de $\mathrm{CO}_{2}$ no sangue arterial $\left(\mathrm{PaCO} \mathrm{CO}_{2}\right)$ mais elevado no sangue arterial e pressão de $\mathrm{O}_{2}$ no sangue arterial $\left(\mathrm{Pa} \mathrm{O}_{2}\right)$ diminuído. A complacência torácica diminui porque, em geral, o tórax do indivíduo obeso apresenta menor elasticidade e maior peso para ser movimentado ${ }^{1}$.

Desequilibrio de Hidratação. Especialmente para o paciente cirúrgico, representa grande risco tanto a desidratação como a hiperidratação, sendo sempre recomendada a correção do equilibrio hidro-eletrolítico, como medida profilática, antes da cirurgia. O paciente hiperidratado pode estar exposto à insuficiência cardíaca, hipopotassemia, edema agudo de pulmão, etc.; e o desidratado apresenta maior propensão para fenômenos tromboembólicos, devido à hemoconcentração e maior facilidade para estase brônquica, com dificuldade de expectoração devida ao ressecamento das vias aéreas ?

Exacerbação das DPOC. O paciente nestas condições apresenta, geralmente, secreção brônquica aumentada e reserva respiratória diminuida com maior possibilidade de complicações pulmonares.

Tabagismo. O fumo diminui a atividade muco-ciliar, importante meio de defesa pulmonar, estando internamente associado a DPOC e ao câncer pulmonar. As complicações pulmonares são três vêzes mais freqüentes nesses pacientes, no período pós-operatório que nos pacientes não fumantes ${ }^{1}$.

\section{Fatores Agravantes}

São fatores agravantes a própria situação cirúrgica, especialmente a das cirurgias abdominais altas e torácicas, que propicia maior risco devido ao ato cirúrgico ser mais prolongado e, portanto maior tempo de anestesia; possibilidade de maior imobilização do paciente no leito, não apenas pela dor como, também, pela presença de drenos; e, ainda, a possibilidade de distensão abdominal, bem como de aspiração de conteúdo gástrico ou oral.

Anestesia. Ocasionam diminuição do reflexo da tosse e da atividade muco-ciliar as drogas anestésicas, substâncias depressoras dos centros respiratórios, usadas por tempo prolongado; o efeito ressecante da medicação com atropina sobre a árvore brônquica; o efeito irritante do "cuff" da sonda de entubação e de aspiração; a administração de gases secos e de elevada concentração de $\mathrm{O}_{2}$. Essa diminuição facilita estase da secreção brônquica e alterações nas trocas gasosas.

Imobilização no leito. É esta muito freqüente na fase pós-operatória; é devida ao enfraquecimento conseqüente ao ato cirúrgico, à incisão e à presença de drenos, inibindo a inspiração e a tosse; é também motivada pela dor e pelo medo do rompimento dos pontos cirúrgicos. Dá 
origem ao acúmulo de secreção, propiciando a insuficiência de ventilação pulmonar e o aparecimento de complicações pulmonares.

Distensão abdominal. É originária ảo efeito colateral dos anestésicos e analgésicos, que provocam a diminuição do peristaltismo e aumentam o meteorismo, dificultando, assim, os movimentos do diafragma, músculo principal da respiração.

Dor. Devido à dor o individuo deixa de tossir o que causa retenção de secreção brônquica e suas conseqüências, além de diminuir a expansão pulmonar por imobilização da caixa torácica e uniformização dos movimentos respiratórios.

\section{CONDUTAS PREVENTIVAS}

Destaca-se como de primordial importância, em todas as condutas de assistência à saúde, a individualização do paciente.

Cada indivíduo, sadio ou doente, é um ser único, com potencial que deve ser explorado nas eventualidades que se apresentem. Não podemos esquecer, entretanto, que o ser humano é complexo, que tem necessidades, não apenas biológicas, mas também psíquicas, sociais e espirituais; todas estas requerem atenção, especialmente de enfermagem, campo de nosso trabalho.

Podemos deduzir, então, que a assistência de enfermagem deve ser individualizada mas, ao mesmo tempo, global em relação a cada indivíduo.

\section{Tal assistência objєtiva:}

Prevenir complicações e contribuir para a cura e reabilitação do paciente, num esforço para fazê-lo retornar ao seu equilíbrio homeostático.

Dividiremos este item em dois tópicos, considerando o paciente na fase pré-operatória e na fase pós-operatória.

\section{Preparo do paciente na fase pré-operatória}

O paciente que se prepara para uma cirurgia, especialmente quando se trata de cirurgia de grande porte, como as torácicas e abdominais altas, precisa ser preparado adequadamente, a fim de que possa melhor colaborar no período pós-operatório. Este preparo deve ser adaptado ao nivel intelectual do paciente e condicionado à suas expectativas a respeito da cirurgia e do atendimento hospitalar, à sua ansiedade e a seus interesses (sondados anteriormente) e executado parceladamente pela equipe de saúde. Para tanto, torna-se importante o bom entrosamento dessa equipe.

Consiste este preparo, em primeiro lugar, em informações de ordem geral, sobretudo se for a primeira vez que o paciente vai ser submetido 
a cirurgia. Se este demonstrar interesse, deve ser informado sobre: as condições da sala de operações (assepsia, aparelhamento, rituais), quem estará com ele durante todo o ato cirúrgico (cirurgiões, anestesistas, enfermeiras, entre outros), para onde será conduzido logo após a cirurgia, em que condições e qual a razão (anestesia, curativos, drenos e outros). Estas informações contribuirão para tranquilizá-lo, aumentar sua confiança na equipe e atenuar possíveis reações psicossomáticas pós-operatórias.

É conveniente que tome conhecimento do tipo da cirurgia a que vai ser submetido, em que região de seu corpo será ela realizada e como vai ser a incisão cirúrgica.

Ao paciente que fuma é recomendada a abstenção do fumo ou sua diminuição para o mínimo possível, durante o período pré-operatório, sendo-lhes explicadas as razões desta medida.

A mobilização no pós-operatório precisa ser enfatizada para o paciente: tanto a mudança de decúbito em períodos regulares e os exercícios passivos e ativos com os membros superiores e inferiores quanto a deambulação precoce. Os dois primeiros ele deverá treinar, após demonstração pela enfermeira.

$\mathrm{O}$ paciente deve ser também orientado quanto ao valor e as restrições da alimentação e quanto à hidratação, tanto no pré como no pós-operatório.

De suma importância é a fisioterapia respiratória. O paciente precisa treinar os exercícios respiratórios e os exercícios de tosse e acostumar-se à tapotagem, tomando conhecimento de que contribuem sobremaneira, para diminuir a incidência de complicações pulmonares, sobretudo nos casos de fumantes e/ou de bronquite crônica. Quanto aos exercícios respiratórios deve ser enfatizada a inspiração profunda, que lhe propiciará eficiente expansão pulmonar e o exercício de tosse e a tapotagem que provocarão mobilização da secreção brônquica, facilitando sua eliminação.

\section{Assistência ao paciente no periodo pós-operatório}

E ponto básico da assistência de enfermagem a manutenção das vias aéreas livres visando a proteção dos mecanismos próprios da defesa das mesmas, que são a atividade muco-ciliar, a tosse e a variação do ar corrente.

Atividade muco-ciliar. A árvore tráqueo-brônquica é revestida de epitélio ciliado e de muco, substância produzida por células secretoras (mucosas e serosas), cuja principal função é a de hidratação das vias aéreas. Os movimentos constantes dos cílios na mesma direção, em conjunto com o muco, ajudam a captação e o transporte de substâncias estranhas inaladas, até as zonas de reflexo da tosse, para sua eliminação ${ }^{8}$. A inalação de ar sem adequada umidificação, associada à hidra- 
tação deficiente do organismo, favorece a desidratação do muco, depressão do movimento ciliar e conseqüente estase de secreção brônquica.

Torna-se, portanto, importante manter a umidificação das vias aéreas, o que pode ser realizado por meio da nebulização, quando necessária, e da hidratação do organismo pela administração de líquidos, por via oral ou parenteral (soros). Esta umidificação, entretanto, deve ser sempre relacionada às condições hemodinâmicas do paciente.

\section{Como já foi visto o fumo deprime a ação ciliar.}

Tosse. Esta combinada com os movimentos ciliares, propicia a limpeza das vias aéreas, arrastando e eliminando as secreções existentes na árvore brônquica. A dor e/ou inconsciência deprimem ou suprimem o reflexo da tosse, causando retenção da secreção brônquica, o que leva a eventual pneumonia.

Para produzir reação tussigena eficiente, o organismo requer, praticamente, toda a capacidade vital, que está em déficit devido a intervenção cirúrgica e que é mais prejudicada nas intervenções abdominais do que torácicas, levando aquelas a complicações pulmonares mais freqüentes do que estas ${ }^{1}$. Além disso, o paciente, geralmente, tem medo da dor que possa sentir e do rompimento de pontos cirúrgicos que possa ocorrer, ao tossir. Ele precisa ser orientado e auxiliado a pressionar a cicatriz cirúrgica com um travesseiro ou lençol dobrado e estimulado a tossir. Se foi bem orientado no periodo pré-operatório, colaborará com maior eficiência. Caso não haja cooperação do paciente e/ou a tosse seja insuficiente, podem-se empregar, como último recurso, medidas mecânicas para estimular a tosse, isto é, a excitação das zonas reflexógenas da tosse por meio de um cateter fino; mas esta medida só deve ser executada sob orientação médica.

Variação do ar corrente (conhecida como suspiro). A quantidade do ar inspirado em cada ciclo respiratório é variável de $200 \mathrm{a} 500 \mathrm{~cm}^{3}$, em condições normais, o que proporciona a expansão intermitente do tecido pulmonar e desfaz microatelectasias ${ }^{7}$.

No pós-operatório, devido à dor e à medicação usada para sedação, o paciente reage com respirações superficiais e regulares, o que favorece a atelectasia, precisando, portanto, ser estimulado a fazer exercícios respiratórios com inspirações profundas, conforme já treinado no pré-operatório.

A observação pelo pessoal de enfermagem é muito importante neste particular; quando o combate à dor for fundamental, no sentido de permitir que o paciente inspire profundamente e tussa, ele poderá receber analgésico, mas sempre com muita cautela; ele precisa ser estimulado para inspirar profundamente e, tossir ${ }^{1}$. $O$ paciente bem preparado no pré-operatório requer menor quantidade de analgésico no periodo pós-operatório ${ }^{1}$. 
Além dos exercícios de tosse e de respiração, outras práticas complementam o que denominamos a "fisioterapia respiratória", tais como, a tapotagem, a mudança de decúbito e a drenagem postural se a quantidade de secreção acumulada assim o exigir. A deambulação regular e precoce deve ser estimulada. Todas estas medidas devem seguir uma programação, com horários determinados.

Preconiza-se, como posição ideal, quando este paciente está no leito, o decúbito semi-sentado; com isto a expansibilidade torácica é facilitada, pois diminui a pressão das vísceras abdominais sobre o diafragma $\mathrm{e}$ pulmões, permitindo inspirações mais profundas ${ }^{10,}{ }^{11}$.

A mudança regular de decúbito previne e/ou alivia processos infiltrativos dos pulmões.

A drenagem postural e a tapotagem têm a finalidade de mobilizar as secreções brônquicas, sendo mais efetivas quando realizadas após nebulização pois esta facilita a sua eliminação.

Identificação precoce dos sinais clínicos de insuficiência respiratória (IR)

A enfermeira pode detectar sinais clínicos que, correlacionados a $\mathrm{Rx}$, gasometria e outros dados laboratoriais, permitem o diagnóstico precoce de insuficiência respiratória aguda, o que constitui condição importante para a recuperação do paciente no pós-operatório.

Segundo alguns autores ${ }^{1,3}$, a sintomatologia clínica do paciente em IR está ligada à presença e à severidade da hipóxia (deficiência de $\mathrm{O}_{2}$ no sangue arterial) e da hipercapnia (aumento dos niveis sanguíneos de $\mathrm{CO}_{2}$ ), acentuando-se quando tais desvios já atingiram graus extremos.

Por isso, torna-se evidente a necessidade de assistência de enfermagem contínua, para que sejam detectadas as alterações iniciais, tanto físicas como de comportamento do paciente, a fim de que haja intervenção mais precoce no tratamento.

Podemos caracterizar como sinais clínicos da insuficiência respiratória aguda (IRA): taquicardia, hipertensão arterial, taquipnéia e o uso de músculos acessórios da respiração, cianose e sudorese ${ }^{3}$.

$\mathrm{Na}$ primeira linha de defesa cardiovascular, que se apresenta contra a hipóxia, estão a taquicardia e a hipertensão arterial; posteriormente, numa fase mais tardia e mais grave, a hipertensão poderá evoluir para hipotensão arterial.

A taquipnéia e a utilização de músculos acessórios da respiração decorrem da tentativa do organismo de compensar a hipóxia, assim como a hipercapnia combinados às alterações do $\mathrm{pH}$.

A cianose, geralmente, aparece quando há $5 \mathrm{~g}$ por cento ou mais hemoglobina reduzida no sangue capilar. Convém notar, que o paciente com acentuada anemia dificilmente demonstrará cianose, sendo, portanto, sempre recomendadas a observação e correlação com o hemograma ${ }^{11}$. 
A sudorese é conseqüente à hipotensão e à hipóxia.

Outras modificações a serem observadas no paciente são as reações que vão desde a expressão de mal estar $e$ irritabilidade até as alterações do nivel de consciência (estupor, coma) e convulsões (na hipóxia severa com $\mathrm{PaO}_{2}$ de aproximadamente $30 \mathrm{mmHg}$ ).

\section{TRATAMENTO}

A gravidade desse quadro, assim como a complexidade da assistência a ser prestada ao paciente exigem uma equipe de enfermagem consciente e preparada para prestar assistência de enfermagem eficaz a fim de evitar, o mais possivel, iatrogenias tais como: infecções por falta de assepsia, lesões de mucosa decorrentes de técnica inadequada de aspiração e outras intercorrências evitáveis.

O tratamento de enfermagem proposto compreende os seguintes cuidados $^{4,9}$ :

a) controle das condições gerais do paciente: temperatura ( $T$ ) ; freqüência cardíaca (FC), pressão arterial (PA), pressão venosa central (PVC); balanço hídrico, condições da circulação periférica (obtidas pela coloração e temperatura da pele), nível de consciência e observação dos sinais precoces de infecção;

b) controle das condições respiratórias pela observação do tipo e da freqüência da respiração $(R)$, quantidade e tipo da secreção brônquica;

c) manutenção da higiene brônquica pela utilização das manobras já citadas de fisioterapia respiratória (tapotagem, drenagem postural, exercícios respiratórios e aspiração de secreção);

d) liquefação da secreção brônquica por meio de hidratação adequada do paciente e da umidificação do $\mathrm{O}_{2}$ inalado (nebulização);

e) combate à hipoxemia desde a administração de $\mathrm{O}_{2}$ por máscara ou cateter até a assistência mecânica contínua e adequada;

f) cuidados corporais necessários à manutenção das condições higiênicas e do conforto, para tentar diminuir, dessa forma, a ansiedade do paciente;

g) prevenção ou diminuição da dor, com a administração cautelosa dos analgésicos prescritos, associada a medidas que propiciem suporte emocional adequado e que favoreçam o repouso necessário;

h) movimentação ativa e/ou passiva dos membros superiores e inferiores, assim como mudança de decúbito, visando a profilaxia de complicações tromboembólicas, escaras e estase de secreção brônquica;

i) administração de alimentação e hidratação adequadas e compativeis com as condiçōes gerais do indivíduo (P, PAA, PVC, diurese). 
Se o paciente estiver entubado, a administração da dieta será feita por sonda nasogástrica, fracionada e lentamente, com observação freqüente da presença de sinais de distensão gástrica.

Quanto à administração de $\mathrm{O}_{2}$ ressalta-se a importância da umidificação correta do gás inalado, pois a falta desta ocasiona o ressecamento das secreções e mucosas e o excesso pode levar ao encharcamento dos pulmões; 0 alto volume de $\mathrm{O}_{2}$ pode ocasionar lesões celulares desde os bronquíolos até as células alveolares ${ }^{6}$. Além do mais é de suma importância a observação e informação da $\mathrm{PaCO}_{2}$ do paciente e de ser ele ou não portador de pneumopatia crônica. E sabido que em condições normais a respiração regulada, principalmente à custa do estímulo do centro respiratório bulbar pela tensão do $\mathrm{CO}_{2}$ sanguíneo. $\mathrm{O}$ aumento da tensão de $\mathrm{CO}_{2}$ estimula o centro respiratório até determinado limite, acima do qual sua ação começa a ser depressiva. Em pacientes com penumopatia crônica e/ou em hipercapnia, o centro respiratório, perdendo a sensibilidade devido à saturação do $\mathrm{CO}_{2}$, transfere o comando da respiração para os centros quimiorreceptores carotídeo e aórtico, dirigidos pelo estímulo da hipóxia. Com a melhora da hipóxia pela administração de $\mathrm{O}_{2}$, a ventilação diminui e a $\mathrm{PCO}_{2}$ aumenta, deprimindo ainda mais o centro respiratório, podendo levar o paciente à narcose, coma e morte ${ }^{5}$. Neste caso, e conforme a complexidade do quadro clínico, é indicada a ventilação mecânica.

O tratamento médico, em geral, é feito à base de antibióticos, corticóides e reposição volêmica adequada, acompanhado de provas radiológicas e laboratoriais.

A par de todos estes cuidados a enfermeira precisa considerar o aspecto psicológico do paciente, procurando adquirir a confiança dele para levá-lo a sentir-se calmo e seguro e atender, dentro do possível, às suas solicitações, explicando a razão das ações executadas.

Como um ser social, pertencente a um núcleo familiar, o paciente não pode ser isolado completamente desse contexto, devendo ser-lhe facultada a visita de familiares, de acordo com o seu estado e o regulamento hospitalar.

O atendimento das necessidades espirituais do paciente não pode ser negligenciado e de acordo com as suas concepções filosóficas e religiosas, a enfermeira deve prestar-lhe assistência ou providenciar para que estas necessidades sejam satisfeitas.

\section{CONCLUSÃO}

A elevada incidência de complicações respiratórias em pacientes hospitalizados ressalta a importância de uma equipe de enfermagem capaz de trabalhar na prevenção dessas complicações, assim como de intervir adequadamente no tratamento das mesmas a fim de diminui-las, por meio da assistência acima proposta. 
VALENTE, M. A. \& IDE, C. A. C. Nursing intervention in surgery to prevent pulmonary complications. Rev. Esc. Enf. USP, São Paulo, 16(3):265-274, 1982.

The authors describe the predisposing factors of post-operative pulmonary complications (old age, malbalanced hydratation and nutrition, exacerbation of chronic obstructive pulmonary diseases) as well as the aggravating factors (anesthesia, immobilization in bed, abdominal distention, pain). They present the objectives of nursing intervention, pre and post operative measures to prevent pulmonary complications, early identification of clinical signs of respiratory failure, and treatment.

\section{REFERENCIAS BIBLIOGRAFICAS}

1 - Allgower, M. \& BeVILACQUA, R. G. Manual de cirurgia. São Paulo, E.P.U. 1981. p. 134-51.

2 - ATUAlizaço dos métodos de prevenção das complicaḉes pulmonares no pós-operatório. São Paulo, Hospital da Beneficência Portuguesa, 1981 (Apostila).

3 - Bethlem, N. Pneumologia. Rio de Janeiro, Atheneu, 1973. p. 352-3.

4-CLINE, B. A. \& FISHER, M. L. Means emergency. Nursing, Horshan, 12(2):63-7, Feb. 1982.

5 - COMROE, J. H. Physiology of respiration. 2. ed., Chicago, Year Book Medical Publishers, 1974. D. 258 .

6 - EVORA, P. R. B., coord. Tópicos de terapia intensiva: Ribeirão Preto, Centro Acadêmico Rocha Lima FMRP-USP. s. d. (Apostila).

7 - GOLDENBerg, S. \& BEVIllaCQUA, R. G. Bases da cirurgia. São Paulo, E.P.U., 1981. p. 119-21.

8 - GOMES, A. M. et alii. Enfermagem na unidade de terapla intensiva. São Paulo, E.P.U., 1978. p. 66-95.

9 - KIRILLOFF, L. H. \& MARZKIEWIEZ, R. C. Guide to respiratory care in critically ill adults. Amer. J. Nurs., New York, 79(11)2005-11, Nov. 1979.

10 - SHERRY, D. Adult respiratory distress syndrome. J. Pract. Nurs., New York, 32(2): 21-3, Feb. 1982.

11 - VALENTE, M. A. A enfermagem na problemática do paciente hospitalizado que apresenta dispnéia. Săo Paulo, 1977. p. 50-2. (Dissertação de Mestrado-Escola de Enfermagem da USP). 